\title{
Arabizi across Three Different Generations of Arab Users Living Abroad: A Case Study
}

\author{
Mariam Haghegh \\ Faculty of Education, Eastern Mediterranean University \\ Famagusta, TRNC
}

Received: 2/24/2021 Accepted: 5/7/2021 Published: 5/24/2021

\begin{abstract}
The study explores the sociolinguistic phenomenon, Arabizi, from a new perspective by investigating the case of three Arabizi users coming from different generations: Azer (42 years old), Nada (29 years old), and Mira (21 years old). The main research question of the study is how generational differences between Arabizi users shape their experiences with Arabizi in terms of 1) how they learned it, 2) how they currently use it, 3) how they perceive its effect on the Arabic language, 4) their attitude towards its users, 5) and their expectations for its future use. Semi-structured interviews were employed to gain a deeper insight into participants' experiences with Arabizi, taking into consideration their linguistic, educational, work, and social backgrounds. The significance of this case study lies in how Arabizi users' surroundings and life experiences influence their linguistic choices and perceptions. Findings provide insight into how Arabizi is considered advantageous compared to using English language. It is also perceived to be a phase for youngsters that will subside in the future as technology develops. The study concludes with recommendations for future research on how Arabizi transforms as its users grow older.

Keywords: Arabizi, case study, code-switching, different generations, Latinized Arabic, Standard Arabic, sociolinguistics, Yamli
\end{abstract}

Cite as: Haghegh, M. (2021). Arabizi across Three Different Generations of Arab Users Living Abroad: A Case Study. Arab World English Journal for Translation \& Literary Studies 5 (2) 156-173.

DOI: http://dx.doi.org/10.24093/awejtls/vol5no2.12 


\section{Introduction}

In order to understand this phenomenon known as Arabizi, we must touch upon the nature of the Arabic language first. The Arabic language is one of the most spoken languages in the world and is the official language in twenty-three Arab countries (Taha, 2015). Its alphabet contains 28 letters, and is read from right to left and written in cursive script (Panović, 2018). The Arabic language has two forms, the Classical Arabic form, 'Al-fusha,', known today by its contemporary variant Modern Standard Arabic (MSA, henceforth referred to as Standard Arabic, $\mathrm{SA}$ ). The second form is the vernacular, which is distributed geographically all over the Arab world and includes Levantine Arabic, Egyptian Arabic, and Gulf Arabic, etc. (Taha, 2015). Although every Arab speaks at least one of these vernaculars in their daily communication, "an educated Arab by definition must add to that a fair mastery of MSA" (Palfreyman \& Al Khalil, 2003, p.9).

Arabizi is the modern-day communication between youngsters on social media and instant messaging applications, where they transcribe their Arabic vernacular in English alphabet as well as numbers, resulting in a Latin-scripted, 'arithmographemic', Arabic slang (Bianchi, 2012; Yaghan, 2008). Arabizi was developed by Arab users at the end of the 1990s. The term is created by combining the Arabic words 'Arabi' and 'Inglizi' (meaning Arabic and English respectively) to produce the hybrid word: 'Arab-izi' (Alghamdi \& Petraki, 2018). Also known as Latinized Arabic, Romanized Arabic, Arabic Chat Alphabet, Arabtini, 3arabizi (Aboelezz, 2012; Bianchi, 2013), Arabish, Franco-Arab, and Youth New Era Language (Akbar, Taqi, \& Sadiq, 2020). Arabizi often has the same characters displayed in Table one:

Table 1. Arabizi symbols

\begin{tabular}{|c|c|c|c|c|}
\hline \multirow{2}{*}{$\begin{array}{c}\text { Phonetic } \\
\text { Description }\end{array}$} & \multirow{2}{*}{$\begin{array}{l}\text { Arabic } \\
\text { Letter }\end{array}$} & \multicolumn{2}{|c|}{ Romanization Possibilities } & \multirow[t]{2}{*}{ Example } \\
\hline & & Arithmographeme & English Letters & \\
\hline$/ \mathrm{R} /$ & $\Leftrightarrow$ & 2 & $\mathrm{a}$ & so2al (question) \\
\hline$/ \mathrm{h} /$ & $\tau$ & 7 & $\mathrm{~h}$ & 7elm (dream) \\
\hline$/ \mathrm{x} /$ & $\dot{\tau}$ & $5-7$ & $\mathrm{kh}$ & So5na/Sokhna (hot) \\
\hline$/ \mathrm{s}^{\mathrm{s}} /$ & ص & 9 & $\mathrm{~s}$ & 9aber (patient) \\
\hline$/ \mathrm{d}^{\mathrm{\varsigma} /}$ & ض & '9 & $\mathrm{d}$ & '9arab/ darab (hit) \\
\hline$/ \mathrm{t}^{\mathrm{f}} /$ & b & 6 & $\mathrm{t}$ & 6ayyara (airplane) \\
\hline$/ \mathrm{d}^{\mathrm{\varsigma} /}$ & ظ & 6 & $\mathrm{z}$ & ‘6abi (gazelle) \\
\hline$/ \mathrm{S} /$ & $\varepsilon$ & 3 & ' & yal3ab (play) \\
\hline$/ 2 /$ & $\dot{\varepsilon}$ & '3 & $\mathrm{gh}$ & '3ayoor (jealous) \\
\hline /q/ & ق & 8,2 & $\mathrm{q} / \mathrm{a}$ & 8areeb/2reeb (relative) \\
\hline
\end{tabular}

Note 1. Adapted from Allehaiby (2013, p.55)

Arabizi is used heavily by Arab bilinguals who were born or have lived abroad. They code-switch and code-mix linguistic features of English or French with their dialect in their 
spoken or written conversations. This is referred to as Latinization, where words are being transliterated from Arabic to Roman orthography along with using English or French vocabulary (Gorgis, 2010, as cited in Akbar et al., 2020). Common Latinized Arabic (CLA) was used in earlier times to provide access to Arabic content such as Quran transcriptions to nonArabic speakers (Aboelezz, 2012). However, Arabizi is now used to communicate between Arabic speakers via Computer-Mediated Communication (CMC) and in online settings, characterized by using numerals for the Arabic sounds that do not exist in English and cannot be represented by Roman script (Aboelezz, 2012).

Kenali et al. (2016) categorized Arabizi into two systems, Basic and Advanced. The basic Arabizi users employ the closest Roman alphabets that could represent Arabic sounds, such as

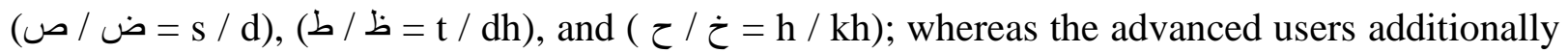

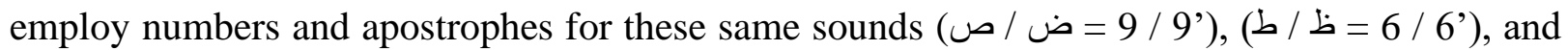
( $\tau / \dot{\tau}=7 / 5$ ) to signal the original sounds in Arabic (Table one). This is what Bianchi (2012) referred to as the use of 'arithmographemes', "numerals as letters for hard-to-translate sounds" (p.1). He noted that the choice is not arbitrary but based on the visual similarity between the Arabic letter shapes and the digits representing them. As shown in Table one, the number ' 3 ' represents the letter $(\varepsilon)$ in the Arabic script and is also an inverse shape of it.

Technology and the internet are considered the leading cause behind the spread of Arabizi. At first, Arabizi used to be a means to communicate in Arabic since technological devices did not support Arabic keyboards (Aboelezz, 2012), later it saved time from switching keyboards between Arabic and English. It was also a money-saving mechanism when text messages were paid by the character, serving as a shorthand to longer Arabic words (Yaghan, 2008). However, Arabizi is now regarded as a modern and 'cool' orthographic system for spoken dialects in many Arab countries (Bahrainwala, 2011).

A wide range of studies conducted on Arabizi examined it from many perspectives. However, since this communication phenomenon has been spreading in the Arab world for the last three decades, Arabizi users belonging to different generations are bound to experience and perceive Arabizi differently. This is due to the exponential technological developments occurring since the 2000s (for generational categories, see Kasasa, 2019). Therefore, the purpose of this study is to present a new way to explore Arabizi. It investigates three case studies of Arabizi users, each coming from a different generation cohort: one from Generation X, born in 1978; the second is a Millennial, born in 1992; and the last is from Generation Z, born in 2000. The study seeks to answer the following research questions with the linguistics backgrounds and generational differences of participants in mind:

(1) How and why were the three participants introduced to Arabizi?

(2) How is Arabizi employed by the three participants? 
(3) How does Arabizi influence the Arabic language skills of participants?

(4) What are the attitudes of participants towards Arabizi and its users?

(5) What are the expectations of participants for the future of Arabzi use?

\section{Literature Review}

\section{The Effect of Arabizi on Arabic}

It is well-known that Arabic dialects differ significantly from SA in terms of grammar, syntax, morphology, and pronunciation. The linguistic context in Arab countries is a typical case of diglossia where SA is used as a formal, high variety in official contexts, and the nonstandard, dialectic varieties are used in everyday speech (Akbar, 2019). Arabizi is thought to be causing an emerging case of triglossia, where it could become another nonstandard variety used with the regional dialect, and replace SA in the Arab print; leading to a language shift in the future (Akbar et al., 2020). Farrag (2012) warned against a similar result of digraphia in Arabic, which "adds to the already existing difficult linguistic situation of Arabic as a diglossic language" (p.48).

There are several campaigns against Arabizi and its users. Some communities reject it and stigmatize its users as tools of westernization and sellouts of their mother language, culture, and religion (Alghamdi \& Petraki, 2018). Most of the studies published on Arabizi in the Arabic language take a critical and judgmental tone and advise against its usage (Alghamdi \& Petraki, 2018). Even Learners of Arabic as a foreign language (AFL) perceive Arabizi as "a kind of a disassociation from the Arabic language" (Farrag, 2012, p.24). Al-Shaer (2016) examined the effect Arabizi had on 420 Palestinian 8th graders' Arabic language by administering an Arabic spelling test. A correlation was found between Arabizi and internet use with weaker Arabic spelling skills. The author (Al-Shaer, 2016) advised against the use of Arabizi to preserve the Arabic language. Taha (2015) also found that respondents saw Arabizi as "a threat to the Arabic language and Arab identity" (p.7).

\section{Arabizi from a Sociolinguistic Point of View}

Alsulami (2019) looked at the sociolinguistic aspects of this phenomenon based on 241 online survey respondents from Saudi Arabia. The study found that the main reasons behind using Arabizi are its function as a code to communicate among youngsters, its more expressive nature, and the absence of Arabic keyboards in some devices. Results showed it was used with friends and peers mainly in informal social conversations and not with parents and older people or within formal contexts, such as academia, business, religion, or literature. Twenty-six participants had a positive attitude towards Arabizi, 17 were negative, while 12 were neutral about Arabizi use. Its perceived advantages were "it is easier and faster to use in communication," and it serves as a code that "cannot be understood by the older generation," (Alsulami, 2019, p.266). In contrast, its disadvantage expressed even by its users was the possible damage it had on the Arabic language, culture, and spelling (Alsulami, 2019). 


\section{Perception towards Arabizi Users}

Another study (Akbar et al., 2020) examined how Arabizi was viewed by 332 Kuwaitis from two different educational contexts in the Kuwaiti community: public and English private schools. Findings show a chasm between private and public schoolers. The first regarded Arabizi to be "a reflection of practicality, innovation, and sophistication," while the latter viewed it as a sign of "arrogance, unfriendliness, shallowness, and (...) effeminacy when used by male Kuwaitis." (Akbar et al., 2020, p.213). While both groups assigned characteristics to Arabizi users such as westernization and bilingualism, public schoolers saw it as a sign of abandoning the Arabic language and identity. In contrast, the English schoolers considered it an advantage of being different, having a dual identity, and being open to others in the world.

\section{Attitude of Arabizi Users}

Alghamdi and Petraki (2018) looked at the attitude of 131 Arabizi users towards Arabizi by employing e-questionnaires and face-to-face semi-structured interviews. The study findings show that Arabizi users regard it as a stylish 'secret code' for informal conversations with their peers on social media, "to control access to what they shared on their social media accounts, and to avoid criticism or monitoring from older people or adults" (p.10). Although they admitted struggling with Arabic language, Arabizi users stated that they do not use it during formal communications (e.g., with teachers, employers, officials, etc.). They emphasize that they are proud Muslims and speakers of the Arabic language who happen to code-switch between Arabic, Arabizi, and English; depending on the addressee and topic at hand. The study concludes that Arabizi helps shape the unique identity of young Arabs and strengthens their group solidarity (Alghamdi \& Petraki, 2018).

\section{Transliterating Arabizi to Arabic Orthography}

Several machine transliteration-based products attempted to fill the gap between Arabizi and Arabic, such as Google Input Tools (www.google.com/intl/ar/inputtools/try) that renders a text in Arabizi to its original Arabic script. The first to do this was Yamli, created in 2007. The name comes from the Arabic "يملي" meaning dictating or transcribing. As described on their website (https://www.yamli.com/), Yamli provides a Smart Arabic Keyboard that offers a "realtime transliteration engine which converts words typed with Latin characters to their closest Arabic equivalent."

Yamli's Smart Arabic Keyboard transcribes from Arabizi to both dialectical and Standard Arabic texts. Figure one shows how Yamli's Arabic Keyboard transcribes words written in Arabizi arjo men siyadatikum alrad back to SA orthography (أرجو من سيادتكم الرد); meaning in English (your response is kindly requested). 


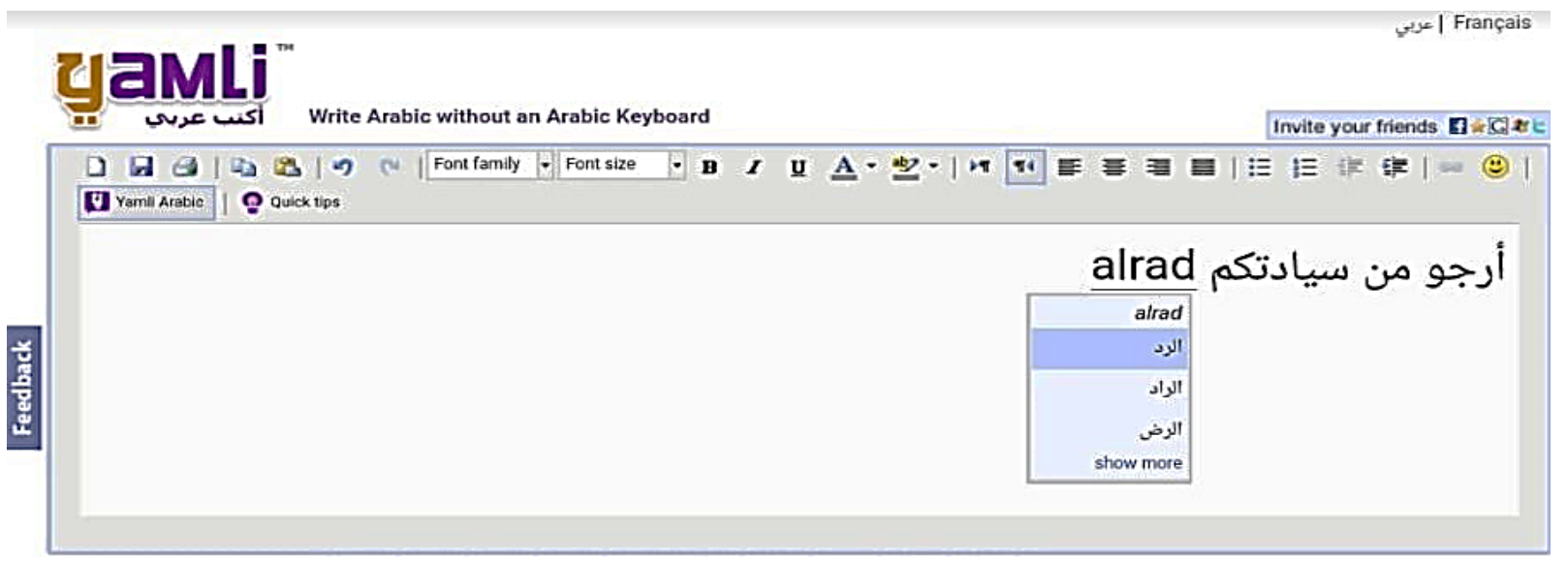

Figure 1. Real-time back-transliteration from Arabizi to Arabic via Yamli's Arabic Keyboard

The literature contains many studies looking at the linguistics and sociolinguistic aspects of using Arabizi (e.g., Akbar, 2019; Al-Shaer, 2016; Alsulami, 2019). However, many examine Arabizi users or non-users by often grouping those of different ages and treating them as one cohort, without considering the diversity and dissimilarity of their experiences with Arabizi and technology as a whole. To exemplify, Alsulami's (2019) participants were between 18 and 35 years old. In contrast, Akbar (2019) differentiates between two generations of Arabizi users in her findings. For example, she noted that the younger generation (18-25 years old) used Arabizi by mixing Roman letters with numbers and apostrophes. Whereas the older generation (26-30), used Basic Arabizi by employing “...conventional Latin alphabets to represent similar sounds” (p.309) and avoiding apostrophized numerals.

\section{Methods}

This case study follows the qualitative research design employing semi-structured interviews conducted with three participants from three different generations. Data collected from the interviews underwent content analysis to answer the research questions.

\section{Participants}

Convenience sampling was employed, where participants were purposefully chosen by the researcher based on their age to represent the three different generations of Arabizi users. A number of acquaintances were contacted to take part or recommend someone who would, on the condition they met the age criteria and were proficient Arabizi users. Two participants were found living in the Turkish Republic of North Cyprus where the researcher was residing at the time of the study, and the third participant was in Lebanon. Azer, Nada, and Mira are the pseudonyms given to the participants. Azer represents the oldest cohort of Arabizi users (Generation X), while Nada represents the Millennials, and Mira serves as a sample for Generation Z. Table two provides demographic information and the linguistic background of the participants. 
AWEJ for Translation \& Literary Studies Volume, 5 Number 2. May 2021

Arabizi across Three Different Generations of Arab Users Living Abroad

Haghegh

Table 2. Demographics and background of the three participants

\begin{tabular}{|l|c|c|c|}
\hline Demographic Information & Azer & Nada & Mira \\
\hline Gender & Male & Female & Female \\
\hline Born in / Age & $1978-42$ yrs & $1992-29$ yrs & 2000 - 21 yrs \\
\hline Nationality & Libyan/British & Libyan & Lebanese \\
\hline Place of birth & UK & Libya & Lebanon \\
\hline Countries lived in & $\begin{array}{c}\text { Libya/Lebanon } \\
\text { Egypt/TRNC }\end{array}$ & $\begin{array}{c}\text { Bahrain/Canada } \\
\text { TRNC }\end{array}$ & Kuwait \\
\hline Education & MA/PhD & BA/MA & BA \\
\hline Work experience & In UK/Libya/Lebanon & In Bahrain & None \\
\hline Friends' nationalities & Multinational & Multinational & Multinational \\
\hline Language spoken at home & Libyan/English & Libyan & Lebanese \\
\hline Language spoken at work & English & Bahraini/English & $/$ \\
\hline Standard Arabic proficiency & Poor & Proficient & Intermediate \\
\hline English proficiency & Native & Native-like & Advanced \\
\hline Messaging App mostly used & WhatsApp & WhatsApp & WhatsApp \\
\hline
\end{tabular}

\section{Instruments}

The interview questions were created after reviewing the literature and its findings on Arabizi. The aim was to see if they applied or not to the participants considering their age differences. The interview questions included items to obtain demographic information such as education, work, linguistic background, and messaging applications used. The rest of the items addressed the five main research questions of the study.

\section{Procedures}

The participants were contacted to set up a suitable time to meet on Zoom. The interviews lasted about an hour and were in the languages (and dialects) the interviewees were most comfortable in. The purpose of the study was explained to the participants clearly to encourage meaningful reflection. All three participants gave their consent for the interviews to be audio/video recorded. The recordings were erased after transcribing them verbatim and any personal information that could disclose the participants' identities was removed from the screenshots accordingly.

\section{Results}

The results of the study are presented based on the content analysis findings regarding the participants' 1) introduction to Arabizi, 2) use of Arabizi, 3) use of Arabic and Arabizi at work and university, 4) code-switching and using Arabizi with non-users, 5) exposure to Arabizi in different contexts, 6) perceptions of Arabizi's effect on their Arabic language, 7) attitude towards Arabizi and its users, 8) expectations of future Arabizi use. Direct quotes of the participants are reported using their initials and ages, i.e. (A42), (N29), and (M21).

Arab World English Journal for Translation \& Literary Studies 


\section{Education and Language Background}

Azer, a 42-year-old Libyan male, was born in the UK and lived in Libya, Egypt, Lebanon, and North Cyprus. The education Azer received abroad and in international schools in Libya was almost completely in English. His Arabic exposure was limited to tutoring lessons for 4-5 years when he was a child. He only used Libyan dialect at home.

Nada, 29 years old, is a Libyan who lived in Canada and Bahrain and mainly attended private English schools. She was taught only two subjects in Arabic: Islamic Studies and Arabic language. Her written SA was exceptionally weak and contained many spelling mistakes. Arabic had negative connotations to Nada due to always obtaining low grades in Arabic subjects. These affected her confidence, resulting in her never typing in Arabic until university. Her primary way of communicating in Arabic was through Arabizi.

21-year-old Mira is a Lebanese student of Translation and Interpretation at a private university in Lebanon. She was born in 2000 and mainly attended private schools in Kuwait and Lebanon from grade 1 to 11. She had a hard time learning Arabic. "I didn't receive the right foundations for Arabic." The only subjects she received in Arabic were Arabic Language, Islamic Studies, and Quran.

\section{Introduction to Arabizi}

\section{Learned by Exposure}

Azer was first introduced to Arabizi by his Egyptian and Lebanese friends when they sent him messages in Arabizi. Azer emphasizes that he did not learn it deliberately "you would just pick it up," confirming Nada's statement, “...we just acquired it by exposure. I never asked someone about the symbols; I just knew them." Unlike Azer and Nada, Mira was introduced to Arabizi by her aunt and later learned how to use it when a friend explained to her the numeral equivalents to the Arabic sounds.

\section{First Impression}

Azer's first impression of Arabizi was understanding, "it made perfect sense." He saw it as people improvising with the limited capacity of the phones at the time lacking Arabic keyboards, text messages being expensive, and people wanting to make the most of a single SMS:

In the past, we were allowed only a number of letters per text message ... It was easier and quicker to express and say what we want in Arabic via Arabizi rather than writing it in English. (A42)

Nada started using Arabizi when she had MSN in 2004. She used Arabizi to communicate with family back home, who could read English but didn't understand it well. Since Nada had no Arabic keyboard, the only solution was to proceed with Arabizi. She never saw it as something weird; it was rather natural and part of being cool back then. Mira started using Arabizi at the age 
of 11 when she got her first phone. Her first reaction when her aunt introduced her to Arabizi was curiosity, "at first, it was really weird to type in this language, but now I got used to it."

\section{Use of Arabizi}

\section{Force of Habit}

Azer regards Arabizi as a "force of habit" for the older generations, which persisted later on, becoming difficult to change. Mira's Arabizi has also become automatic and unconscious, and she would catch herself typing in Arabizi even when she meant to use Arabic. Figure two shows a sample of a recent Arabizi conversation Mira had with a friend.

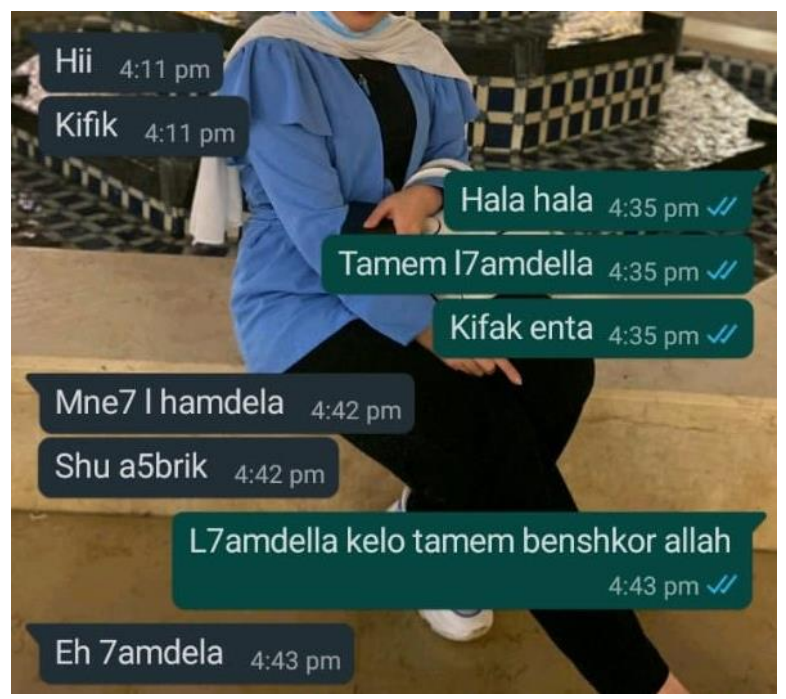

\section{English Translation \& Arabic Script:}

Friend: Hi, how are you?

(كيفك؟)

Mira: Hi, hi! I'm good, thanks to God. How are you?

(هلا هلا تمام الحمد لله، كيفك إنت؟)

Friend: Good, thank God. What's up?

(منيح الحمد لله شو أخبارك؟)

Mira: All well, we give thanks to God.

(الحمدلله كله تمام بنشكر الله)

Figure 2. Sample of a recent conversation in Arabizi between Mira and a friend.

\section{Faster Texting}

Nada, on the other hand, uses Arabizi when she knows the other person understands it. "It's easier because my keyboard by default is in English." A key characteristic of online texting is speed. Even when she could switch to Arabic keyboard, she would be slow to locate letters on the keyboard; therefore, it was faster to use Arabizi, as she was used to the English keyboard. Moreover, Nada points out that there are words shorter and more expressive in Arabic than in English. For example, she would type the single Libyan word (وينك؟) as 'wenik?' in Arabizi, instead of using the equivalent English sentence of three words 'where are you?' to save time and space and ensure being understood faster by the reader.

\section{Arabic vs. Arabizi at Work and University}

\section{Transliterating Arabizi to Arabic Script}

Due to his education, Azer faced problems with Arabic when he started working with Arab institutions and nationalities, "I can't write a letter or an email in Arabic confidently." He was later 
introduced to Yamli and started using it around 2015 in Beirut.

I had to use Yamli to reply to emails. We usually have assistants to whom we dictate what to write in Arabic. But if it was a short email, I use Yamli to make sure the spelling is correct. (A42)

Even though Yamli is very accurate, Azer would still ask somebody to check if it was an important email. He would only use Yamli for transcribing from Arabizi to SA, and not to an Arabic dialect. "If it's informal, I'd change to Arabic keyboard; I wouldn't care about spelling mistakes".

\section{Relearning Arabic in the Workplace}

Nada continued using Arabizi exclusively until she started work in Bahrain. It was then when she began typing in Arabic letters. She used to google every word to make sure the spelling was correct. Her employer would give her handwritten emails and reports in Arabic and ask her to type them. She believes her Arabic improved when she was put in a situation where she was exposed to Arabic without being forced to learn it. She has the belief that using Arabizi in workrelated contexts is not professional.

\section{Influence of Educators on Younger Users}

As for Mira, she faced many challenges at university when translating to Arabic; however, Translation helped her learn SA and its rules. Her Arabic improved as her professors raised her awareness of the damaging impact Arabizi had on her language skills and encouraged her to concentrate on her Arabic more. Yet, she still has difficulty typing in Arabic when doing translation assignments. "I get stuck a lot and keep looking for letters on the keyboard because I'm not used to it. I often pray that my homework would be a translation assignment to English and not Arabic". (M21)

\section{Code-switching and Arabizi with Non-users}

\section{Accommodating to the Language Preferences of Others}

Nada practices code-switching in her work communications daily. She uses English with those who understand it, and SA mainly for work-related email. As for text messaging with colleagues, Nada uses what she calls the 'White Dialect', where the general tone of her message reflects Bahraini dialect, but words that are exclusively Bahraini are substituted with ones less identifiable with any single dialect which can be understood by every Arab. This is because SA is considered too formal for instant messaging, while English is impractical as $25 \%$ of her colleagues do not speak English, and Arabizi is very informal and unprofessional and runs the risk of not being understood.

Nada does not use Arabizi when texting service providers (e.g., her bank) or with adults (e.g., her mother) who don't understand it. "I would make an effort to switch my keyboard and 
reply in Arabic script". She would not, for example, text in Arabizi with someone she is not wellacquainted with unless that person indicates they can proceed with the conversation in Arabizi by using it. She would accommodate to the language the other has texted in, except if it is someone she knows very well.

\section{Arabizi to Signal Informality}

Azer relies on English in most of his communications. However, he would use Arabizi deliberately in work-related emails which are not too formal and do not require SA -to establish friendliness. "I'd rather send an email in Arabizi and not in English if I'm used to speaking to that person in Arabic". Figure three is an example of Azer's last email sent in Arabizi to a nonuser friend.

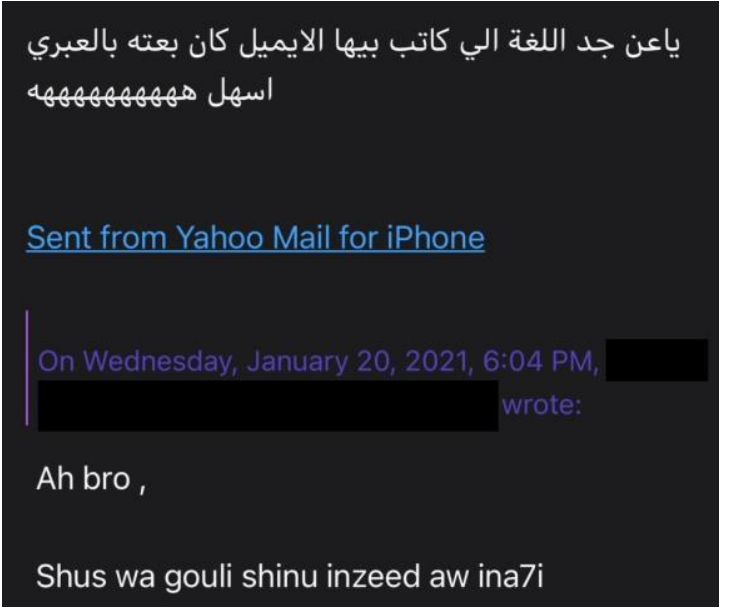

\section{English Translation \& Arabic Script:}

Azer: Hey bro, take a look and tell me what to add or remove.

(أه برو، شوف وقولي شنو نزيد أو نحي).

Friend: Damn this language you write in, it

would've been easier if it was in gibberish, hahaha.

Figure 3. Example of Azer using Libyan Arabizi with a non-Arabizi user.

\section{Avoiding both Arabic and Arabizi}

Mira, however, never writes in Arabic, only in Arabizi. She may switch to English with family and friends, but not to Arabic script. Even when her parents and grandparents write to her using Arabic script for Lebanese dialect, she replies in voice messages, because they might not understand her Arabizi. "I would feel insecure if somebody writes to me in Arabic. It is not how I express myself". (M21)

\section{Arabizi in Different Contexts}

Arabizi in Linguistic Landscapes

Azer has seen Arabizi in logos of restaurants, cafes, and bars in Egypt and Lebanon. Nada notes that Arabizi is used in advertisements, projects, and announcements targeting younger generations in Bahrain. Figure four reveals how an initiative done with the Ministry of Education in Bahrain is promoted in Arabizi to draw the attention of young people online. 


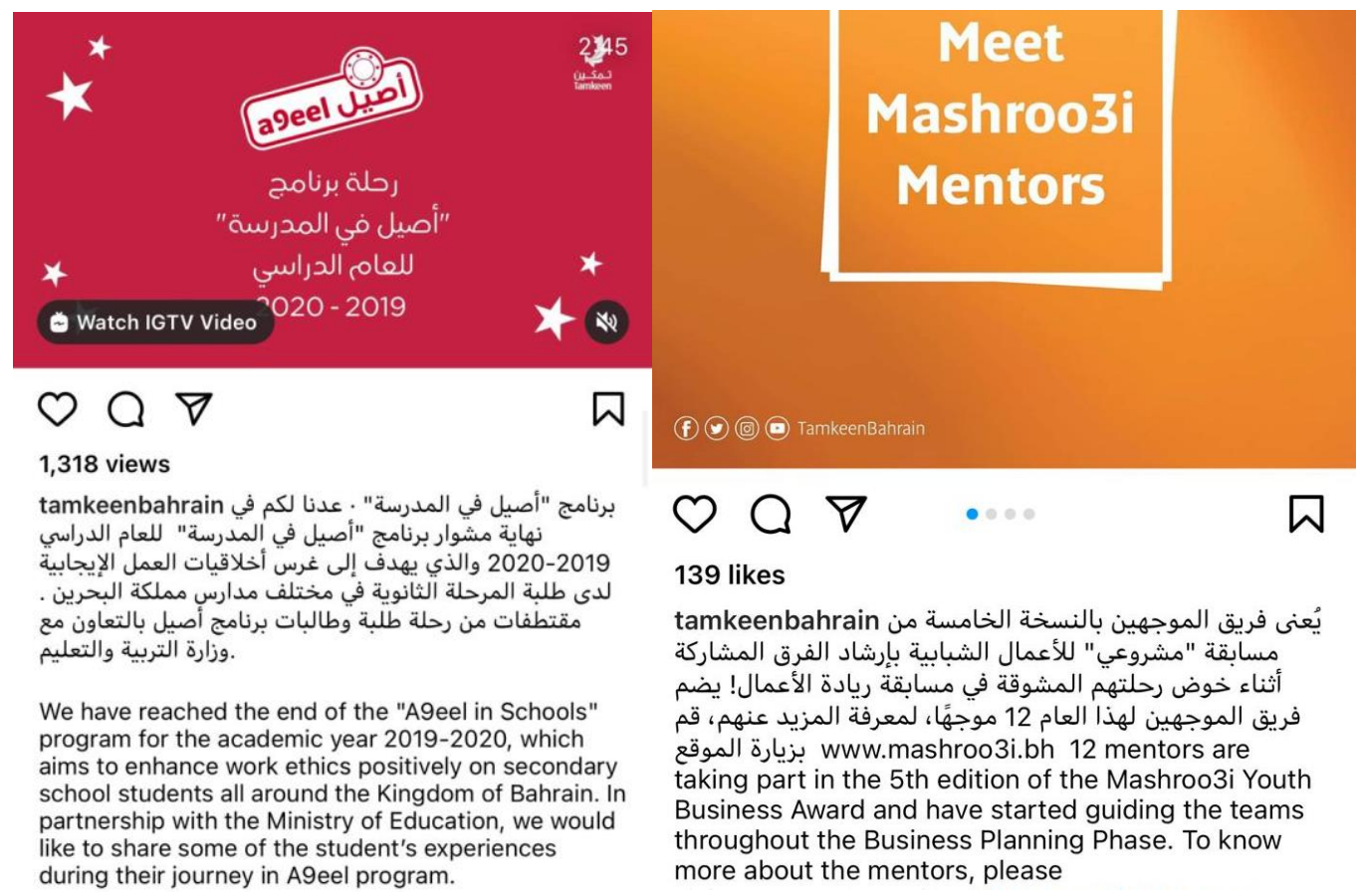

Figure 4. Example of project logos in Arabizi a9eel (أصيل) and mashroo3i (مشروعي) in Bahrain

\section{Different Arabizis}

Azer does not know any Libyan friends who use Arabizi “...except those who are from a similar background to mine and were in contact with the same Arab nationalities I was". He also noted that Arabizi was mostly used in Lebanon and Egypt; however, now in Lebanon, it is widespread. "Unlike Egypt, many people there speak English or French as a second language, and they go to private schools". He asserts that he never received a text which was in Arabic from a Lebanese person. This confirms Mira's testimony that approximately all Lebanese people use Arabizi.

Due to variations in dialects, Arabs from different nationalities often have different Arabizi spellings of the same Arabic word, even with people from the same nationality. For instance, Nada and her husband are both Libyan and speak Libyan dialect; however, they use different spellings of the same Libyan word in Arabizi. Figure five shows a screenshot of her conversation with her husband and how they spell the phrase (نحبك) -meaning 'I love you'-in Arabizi differently from each other. 


\section{La illah ila Allah \\ Inhibak \\ N7bek akter xxx \\ Arrived baby \\ 7mdilah kol shay tamam w easy \\ took me 10 minutes from the plane to the lounge as \\ Hamdillah 3salama baby}

Figure 5. Different Arabizi spellings for (نحبك) = 'I love you': Inhibak / N7bek.

\section{Ubiquitous Code among Young Arabs}

Although Azer and Nada believe that Arabs from different nationalities have different Arabizi, Mira points out that there is not a big difference between Lebanese and Egyptian Arabizi. She has never experienced difficulty understanding young Arabizi users from other nationalities. This suggests that recently Arabizi has developed to be comprehensible by all young Arabs. Mira goes on to say, "I've never met a young Arab using Arabic in texting. Even in serious situations such as the death of someone. It has taken over our lives. It is a lifestyle". (M21)

\section{Effect of Arabizi on the Arabic Language}

Arabizi Negatively Affecting Arabic Spelling

When asked if she thinks Arabizi is affecting her spelling in Arabic, Mira responded, "Hell, yeah!" According to her, Arabizi did affect her Arabic language development. She attributes her improvement in Arabic to her university instructors, who tried to steer her towards Arabic. They view Arabizi negatively and once confronted her by asking, "why do you write like this. It's not understandable!". Perhaps her opinion that Arabizi is affecting her Arabic spelling was influenced by her professors, whom she holds in high regard. She continues by saying “...we need to spread awareness about the importance of our mother language, to promote using proper Arabic in the world. This is what I wish for the next generations." (M21)

Azer agreed that the use of Arabizi could be correlated with poor Arabic spelling skills. "If I hadn't used Yamli, I would've checked with a dictionary for spelling. It would take me longer, but at least I would've learned how to spell the word". But he stated he would not go as far as saying it is a danger to Arabic and Arabizi users' language skills. "I don't think we need to do anything to preserve Arabic because Arabizi users will ultimately work in their countries in the public sector. They will have to conduct all legal, governmental, and official communications in Arabic." (A42) 


\section{Education as the Main Cause of Arabic Regression}

Nada, however, does not believe Arabizi had a direct effect on her language skills. She mainly attributed her weak spelling skills to studying abroad at international schools, where she learned English first before Arabic. When her Arabic improved due to work, she realized she had only resorted to Arabizi to help fill the gap in between.

Arabizi did not affect my Arabic skills. I started using Arabizi first before Arabic because my English was always better. It's not as if my Arabic was good and then got worse because of Arabizi; I had no Arabic in the first place. (N29)

\section{Attitude towards Arabizi and its Users}

Users Oblivious to Arabizi's Growing Popularity

Azer was surprised to know that Arabizi is still widely used among young Arabs. He believed with the advent of smartphones and the availability of Arabic keyboards people would use Arabic more.

If you are an Arab, and your Arabic is good, and you can say what you want to say in Arabic and your audience are Arabs who can write and read in Arabic, then why not write in Arabic? (A42)

\section{Irrelevance to Class, Education, or Gender}

Azer stated that the use of Arabizi may reflect the social class and educational level of the individual only in certain countries such as Egypt. In Lebanon, however, it is used by everyone regardless of their background, which Mira confirms by saying "in Lebanon, it is not exclusive to gender, age, educational background or socio-economic class". Azer acknowledges that in certain conservative societies Arabizi users can be regarded as westernized and effeminate (in the case of male users). Although Mira refutes that using Arabizi is an indication of gender roles, Azer attributed this only to some societies which reject anything foreign, seeing it as a defeat to the western influence on their culture.

Nada concurs that Arabizi use is not related to income level or education and that it does not have any added significance, "It would be just as if I had read it in Arabic". Nada's perception of Arabizi seems to have evolved. She used to think it was a sign of sophistication, but now she believes it is more impressive if someone is proficient in both languages, i.e., English and Arabic (written and spoken).

\section{Expectations for Future Arabizi Use}

Azer believes that Arabizi is being used much less than before because of technology development "it's all about technology and how we move with it." He believes that later on, technology will be so much advanced, that it will allow people to dictate whatever they want to 
say in any language, which in turn will be transcribed to any language they want. According to Nada, Arabizi is only a phase younger Arabs go through, which they eventually outgrow. She noted that most of her old school friends, who never used Arabic script before (only Arabizi), are now posting and commenting in Arabic online all the time. As for Mira, she believes it is a personal choice, "everyone has the right to communicate and type in whatever language they like, however it makes them comfortable". But at the same time, she goes on to say that, "I wouldn't encourage my children to use Arabizi. I'd be worried about their Arabic."

\section{Discussion}

We can see from the participants' accounts of their experience with Arabizi that the reasons they use it and the way they navigate their communications differ from each other. Generation X has developed Arabizi to meet a specific need. As they continued using it out of habit, it appears that they have handed it down inadvertently to younger generations, without realizing the longterm impact it would have. In fact, Generation Z's first introduction to Arabizi was by an elder relative. This indicates that the typical trend of being first introduced to Arabizi by peers and friends in the literature (Alsulami, 2019) has shifted towards older family members belonging to Generation X.

The study reports findings similar to Alsulami (2019) and Yaghan (2008), where the lack of Arabic keyboards and the time-consuming act of changing keyboards are some of the reasons why Arabzi is used; in addition to being easier and faster (Alghamdi \& Petraki, 2018; Alsulami, 2019). Arabizi was also perceived as more expressive compared to Classical Arabic language (Alsulami, 2019; Bahrainwala, 2011; Taha, 2015); allowing users to "express their dialects in a written form" (Alsulami, 2019, p.265). However, one of the most significant findings of this study is that the use of Arabizi is not only considered advantageous in comparison to Arabic, but it is also perceived as more expressive and time-efficient compared to using English language. Participants found that typing the one-word Arabic question wenik? in Arabizi is much faster than typing the triple-word English equivalent 'where are you?'

Moreover, all participants agree that Arabizi is only a means of communication that could be used by anyone regardless of gender, age, social class, or education. Yet, other studies (Alsulami, 2019; Palfreyman \& Al-Khalil, 2003) have identified that Arabizi is used more among educated people. In terms of social class, all generations reject that Arabizi reflects the "sophistication" of its users (Akbar et al., 2020, p. 210). However, this might not have always been the case for Millennials, who seem to have outgrown associating Arabizi with prestige, which indicates growing awareness among users. In general, the participants had a positive attitude towards Arabizi, which can be attributed to the fact they had studied in private and international schools. This confirms with Akbar et al. (2020), who found that the type of school attended by participants was the only variable that significantly influenced their view of Arabizi. 
Regarding its effect on the Arabic language, the participants realize that their low Arabic level is due mainly to educational factors, and not Arabizi solely. Similarly, Alghamdi and Petraki (2018) found that having difficulties with the Arabic language was one of the reasons why youngsters resort to Arabizi in the first place, which was the case for Millennials in this study. Still, the oldest and youngest generations admit that their Arabic would have been better had they not been using Arabizi. Regardless of the state of their Arabic language, Arabizi users have clear rules about when and with whom to use Arabizi. This corroborates other studies (Alghamdi \& Petraki, 2018; Alsulami, 2019) that found users respect the cultural boundaries that come with Arabizi use and regard it inappropriate during formal occasions. In such cases, Generations $X$ and Y seem to be more adaptable to code-switching and accommodating to others' languages and scripts than the youngest generation. Generation $\mathrm{Z}$ seems too immersed in Arabizi and would do anything to circumvent using Arabic, including code-switching to English or sending voice messages in Arabic.

We could also see how work has a significant impact on the participants' Arabic language. Although the older generation user still opts for the help of assistants or resorting to transcribing applications such as Yamli. Millennials have adapted to their job requirements and have become proficient in using Arabic for work purposes. We also learned not to undermine the influence of professors and teachers on the youngest generation's views of Arabizi and the importance of Arabic language. All three participants affirm that Arabizi does not affect their identity as Arabs and Muslims and reject wholeheartedly any assumptions suggesting otherwise. The same sentiment was held by Arabizi users in Alghamdi and Petraki (2018).

Finally, users perceive the future of Arabizi differently as well. While the older generation believes it will die down as technology develops and texting becomes obsolete, Millennials regard it only as a phase for young people, which they will abandon once they start their careers. Generation $\mathrm{Z}$ seems to be conflicted as they regard Arabizi as part of freedom of expression, but at the same time, its negative impact on their Arabic skills makes them wary of its use.

\section{Conclusion}

This study contributes to the growing research on the widespread of Arabizi by addressing the gap in the literature and investigating Arabizi from the point of view of three different generations of its users. The study has a semblance of longitudinal research regarding how Arabizi use could differ and change over the years as its users get older. The main findings of the study highlight the similarities and discrepancies among the experiences of Arabizi users belonging to different generations in terms of introduction to and use of Arabizi; attitude towards Arabizi and its users; using Arabizi at work and university; code-switching and using Arabizi with non-users; the effect of Arabizi on their Arabic language; and finally, expectations for future Arabizi use. 


\section{Limitations and Recommendations for Further Research}

Considering this is a case study of three Arabizi users from three generations, conducting wide-scale qualitative research and including more participants from each age group would provide more insightful and generalizable results. Controlling for variables such as the countries the participants come from and have lived in, as well as ensuring a relatively similar education among the sample can render it more representative. Further research could focus on Arabizi users from one linguistic background for more reliable findings. Cross-cultural, cross-dialectical, and longitudinal studies can also provide more insight on how the use of Arabizi differs from one context to another and the changes it undergoes as users get older.

\section{About the Author:}

Mariam Haghegh is a research assistant at Eastern Mediterranean University. She received her BA in Translation Studies from Tripoli University in 2015. She is certified EFL instructor and is currently doing her MA in English Language Teaching at EMU. ORCID ID: https://orcid.org/0000-0003-0647-9430

\section{References}

Aboelezz, M. (2012). We are young. We are trendy. Buy our product! The use of Latinized Arabic in edited printed press in Egypt. United Academics Journal of Social Sciences, 2, 48-72. Retrieved

from https://www.academia.edu/1481874/_We_are_young_We_are_trendy_Buy_our_pr oduct_The_use_of_Latinized_Arabic_in_printed_edited_magazines_in_Egypt

Abu-Liel, A. K., Eviatar, Z., \& Nir, B. (2020). Arabic teenagers' attitudes to electronic writing in Arabizi. Journal of Cultural Cognitive Science. doi:10.1007/s41809-020-00057-2

Akbar, R. (2019). Arabizi among Kuwaiti youths: Reshaping the SA orthography. International Journal of English Linguistics, 9(1), 301-323. doi:10.5539/ijel.v9n1p301

Akbar, R., Taqi, H., \& Sadiq, T. (2020). Arabizi in Kuwait: An emerging case of digraphia. Language \& Communication, 74, 204-216. doi:10.1016/j.langcom.2020.07.004

Alghamdi, H., \& Petraki, E. (2018). Arabizi in Saudi Arabia: A deviant form of language or simply a form of expression? Social Sciences, 7(155). 1-19. doi:10.3390/socsci7090155

Allehaiby, W. H. (2013). Arabizi: An analysis of the Romanization of the Arabic Script from a sociolinguistic perspective. Arab World English Journal, 4(3), 52-62. Retrieved from https://awej.org/images/AllIssues/Volume4/Volume4Number3Sept2013/5.pdf

Al-Shaer, I. M. R. (2016). Does Arabizi constitute a threat to Arabic? Arab World English Journal, 7(3), 18-30. doi:10.24093/awej/vol7no

Alsulami, A. (2019). A sociolinguistic analysis of the use of Arabizi in social media among Saudi Arabians. International Journal of English Linguistics, 9(6), 257-

270.doi:10.5539/ijel.v9n6p257

Arab World English Journal for Translation \& Literary Studies 
Bahrainwala, L. (2011). 'You say hello, I say mar7aba': Exploring the digi-speak that powered the Arab revolution. (Unpublished Master's thesis) Michigan State University, Michigan. Retrieved from https://d.lib.msu.edu/etd/720/datastream/OBJ/View/

Bianchi, R. M. (2012). 3arabizi - When local Arabic meets global English. Acta Linguistica Asiatica, 2(1), 89-100. doi: 10.14746/ssllt.2012.2.4.3

Crystal, D. (2006). Language and the Internet, 2nd ed. Cambridge: Cambridge University Press. doi: $10.1017 / \mathrm{CBO} 9781139164771$

Farrag, M. (2012). Arabizi: A writing variety worth learning? An exploratory study of the views of foreign learners of Arabic on Arabizi. (Unpublished master's thesis) The American University in Cairo, Cairo. Retrieved from http://dar.aucegypt.edu/handle/10526/3167

Kenali, A., Yusoff, N., Kenali, H., \& Kamarudin, M. (2016). Code-mixing consumptions among Arab students. Creative Education, 7(7), 931-940. doi:10.4236/ce.2016.77097

Palfreyman, D., \& Al Khalil, M. (2003). “A funky language for teenzz to use:” Representing Gulf Arabic in instant messaging. Journal of Computer-Mediated Communication, 9(1). doi:10.1111/j.1083-6101.2003.tb00355.x

Panović, I. (2018). 'You don't have enough letters to make this noise': Arabic speakers' creative engagements with the Roman script. Language Sciences, 65, 70-81. doi: 10.1016/j.langsci.2017.03.010

Taha, M. (2015). Arabizi: Is code-switching a threat to the Arabic language. Proceedings of The Asian Conference on Arts \& Humanities (ACAH2015). American University of Sharjah, UAE: The International Academic Forum. Retrieved from http://papers.iafor.org/wp-content/uploads/papers/acah2015/ACAH2015_13058.pdf

Yaghan, A. (2008). Arabizi: A contemporary style of Arabic Slang. Design Issues, 24(2), 39-52. doi:10.1162/desi.2008.24.2.39 